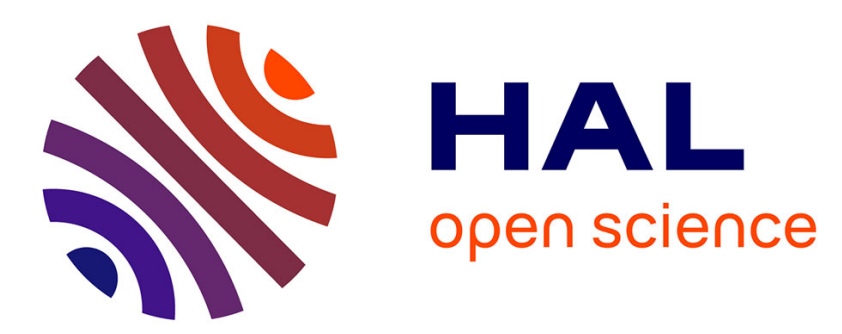

\title{
Competitive adsorption between fluoride and natural organic matter onto activated alumina
}

Meral Mouelhi, Sylvain Giraudet, Abdeltif Amrane, Béchir Hamrouni

\section{To cite this version:}

Meral Mouelhi, Sylvain Giraudet, Abdeltif Amrane, Béchir Hamrouni. Competitive adsorption between fluoride and natural organic matter onto activated alumina. Environmental Technology, 2016, 37 (18), pp.2326-2336. 10.1080/09593330.2016.1149521 . hal-01274116

HAL Id: hal-01274116 https://hal-univ-rennes1.archives-ouvertes.fr/hal-01274116

Submitted on 23 May 2016

HAL is a multi-disciplinary open access archive for the deposit and dissemination of scientific research documents, whether they are published or not. The documents may come from teaching and research institutions in France or abroad, or from public or private research centers.
L'archive ouverte pluridisciplinaire HAL, est destinée au dépôt et à la diffusion de documents scientifiques de niveau recherche, publiés ou non, émanant des établissements d'enseignement et de recherche français ou étrangers, des laboratoires publics ou privés. 


\section{Competitive adsorption between fluoride and natural organic matter onto activated alumina}

Meral Mouelhi ${ }^{\mathrm{a}}$, Sylvain Giraudet ${ }^{\mathrm{b}, \mathrm{c}}$ *, Abdeltif Amrane ${ }^{\mathrm{b}, \mathrm{c}}$, Béchir

Hamrouni $^{\mathrm{a}}$

${ }^{a}$ University of Tunis El Manar, Faculty of Sciences of Tunis, Desalination and Water Treatment Research Unit, El Manar II 2092, Tunis, Tunisia.

${ }^{b}$ Ecole Nationale Supérieure de Chimie de Rennes, CNRS, UMR 6226, 11Allée de Beaulieu, CS 50837, 35708 Rennes Cedex 7, France

${ }^{c}$ Université européenne de Bretagne

Emails: mouelhimeral@gmail.com; sylvain.giraudet@ensc-rennes.fr;

abdeltif.amrane@univ-rennes1.fr; bhamrouni@gmail.com

*Corresponding author:

Dr Sylvain Giraudet

Email: sylvain.giraudet@ensc-rennes.fr

Tel. (+33)2 23238015 


\title{
Competitive adsorption between fluoride and natural organic matter onto activated alumina
}

\begin{abstract}
Natural organic matter (NOM) is a major water constituent that affects the performance of drinking water treatment processes and the quality of drinking water. Besides, several studies have shown that NOM can be adsorbed on the surface of oxides being thereby able to compete with other ions. The overall goal of this study was essentially to investigate the competitive adsorption between fluoride and NOM on activated alumina (AA). For this purpose, a commercial salt of humic acids (HA) was used as a model compound for NOM. The interaction of NOM with fluoride, the simultaneous competitive adsorption, and the effect of preloading AA with NOM were investigated. The UV/Vis absorbance of $\mathrm{HA}$ in the range $200-800 \mathrm{~nm}$ was measured and the specific absorbance SUVA $_{254}$ was determined. High pressure size-exclusion chromatography measurements confirmed the adsorption of aromatic fractions of NOM onto AA and the absence of leaching of the released fractions before equilibrium time. Experimental results indicated that the presence of HA in the system inhibited the adsorption of fluoride onto AA. It was also observed that percentage of removal using fresh AA decreased from $70.4 \%$ to $51.0 \%$ in the presence of HA and this decrease was more pronounced using preloaded AA with HA, reaching $37.7 \%$. Furthermore, competitive adsorption studies were conducted to evaluate the interference of coexisting ions and their effect on fluoride removal capacity, showing a severe impact of the presence of phosphate on the removal capacity unlike nitrates and sulphates, which slightly improved the fluoride sorption.
\end{abstract}

Keywords: Competitive adsorption; Fluoride; Natural organic matter; Alumina; Defluoridation. 


\section{Introduction}

The presence of fluoride in natural waters represents a potential threat to water quality and human health. Beyond the guidance value set by the World Health Organization (WHO) $\left(1.5 \mathrm{mg} \mathrm{L}^{-1}\right)$ [1], excessive exposure to fluoride in drinking water can cause serious troubles such as bone or dental fluorosis. Among the various techniques available for defluoridation, adsorption process is widely used and seems to be the most attractive method in term of cost and simplicity of operation [2]. Adsorption is a robust technique for removing fluoride ions found in some groundwater, at low concentrations but above the permissible limits. The principle behind this technique is that fluoride is transported by diffusion from the bulk phase to the solid surface where it is bound at the surface or interface between two phases by either chemical or physical forces.

Activated alumina (AA) is considered to be the most effective and widely used adsorbent for defluoridation of drinking water, benefiting from the high affinity between aluminum and fluoride ions, which leads to large adsorption capacities [3]. In fact, the removal of fluoride by AA is an established treatment technology that has been, and is still, used for small- and large-scale water treatment plants. The WHO classifies AA adsorption as one of the best demonstrated available technology for fluoride removal [4]. AA is a highly porous adsorbent made of aluminum oxide, $\mathrm{Al}_{2} \mathrm{O}_{3}$; its surface is polar and amphoteric with both acidic and basic characteristics [5].

Most of defluoridation investigations using alumina dealt with the fluoride removal in (ultra)pure water [6,7]. However, in practice, raw waters to be treated by adsorption processes contain more than a single adsorbable compound, and are complex mixtures of ions, organic compounds, suspended matters, etc. These raw waters contain not only defined micropollutants but also ubiquitously occurring natural organic matter (NOM), 
which is a mixture of different natural compounds, such as humic or fulvic acids. Consequently, the presence of NOM in drinking water sources may affect the interactions between fluoride ions and the surface of AA, since these organic compounds might be adsorbed onto the adsorbent or interact directly with fluoride ions. Thus, lower efficiencies for the removal of fluoride could be expected in the presence of NOM. To our knowledge, few studies [8] focused on this particular aspect although the study of the NOM impact on fluoride sorption seems important and useful to improve our understanding of the role that NOM plays in the adsorption process and to consider optimization of this process for the production of drinking water.

In natural waters, NOM is typically found at concentrations between 1 and $50 \mathrm{mg}$ $\mathrm{L}^{-1}$ [9]. Its exact qualitative and quantitative composition is unknown; only the total concentration can be measured by the help of global parameters such as dissolved organic carbon (DOC). NOM results from the degradation of plants and animals and consists of aromatic, aliphatic, phenolic, and quinonic structures with varying molecular sizes and properties [10].

Humic acids (HA) typically represent a large portion of NOM distributing in soils, sediments and waters [11]. It is a chemically heterogeneous compound with various functional groups with different configurations and proportions. Several studies have shown that NOM may compete with target pollutants for adsorption onto alumina surfaces by reducing their sorption rates and equilibrium capacities.

Kumar et al. [12] showed that HA strongly influences the sorption of technetium on alumina under reducing conditions. Likewise, Wang et al. [13] found that the presence of HA affects significantly the sorption of Eu (III) on alumina. On the contrary, Xiao et al. [14] found that in the presence of HA, the sorption of $\mathrm{Zn}$ (II) onto $\gamma$-alumina is enhanced at $\mathrm{pH}<7$, but decreased at $\mathrm{pH}>7$. At lower $\mathrm{pH}$, the sorption process was 
mainly driven by ion exchange and surface complexation whereas, at higher $\mathrm{pH}$, inner particle complexation was dominating. Besides, effects of HA on the adsorption of some heavy metals by $\gamma-\mathrm{Al}_{2} \mathrm{O}_{3}$ were reported by Tang et al. [15], who mentioned that HA enhanced the interaction of $\mathrm{Cu}$ (II) with alumina, but had little effect on the interaction of Cd (II) with the same adsorbent; while Ni (II) sorption is enhanced at low $\mathrm{pH}$ and reduced at high $\mathrm{pH}$ in the presence of HA.

In general, the NOM impact on micropollutant adsorption can be explained by two different mechanisms: 1/ a direct competition of NOM fractions and the micropollutant within the micropore system, referred to site competition; $2 /$ an intraparticle pore blockage where it is assumed that larger NOM molecules accumulate in the pore system (in particular in the mesopores) and hamper the transport of micropollutant to the adsorption sites located in the micropores [16].

However, the knowledge about competitive mechanisms governing fluoride sorption onto AA in the presence of NOM is limited although it could be of great interest from an industrial point of view. In a previous work [17], the decrease observed in the removal of fluoride in groundwater sample, in comparison with the removal in pure water, was attributed to the presence of NOM. Thus, the overall goal of the present study was to investigate the competitive adsorption between fluoride and NOM in order to evaluate the performances of AA. In this work, commercial Aldrich ${ }^{\circledR}$ Humic Acids (AHA) was used as a model compound for NOM. AHA has been widely used as a model NOM [18,19]. It is a brown coloured mixture of not-well-defined macromolecules with polymeric, phenolic and heterocyclic structures containing carboxyl groups and nitrogen functionalities. As reported by Ivanov et al. [20], the AHA has an elemental composition of $39.03 \% \mathrm{C}, 4.6 \% \mathrm{H}, 0.61 \% \mathrm{~N}, 0.957 \% \mathrm{~S}, 8.7$ 
$\% \mathrm{Na}$ and $1.4 \% \mathrm{Ca}$. The effect of $\mathrm{pH}$ and the competitions with some co-existing ions (nitrates, phosphates, and sulphates) were also investigated.

\section{Materials and methods}

\subsection{Reagents}

All reagents used were of analytical grade. Water was obtained from a Milli-Q water purification system (conductivity $<10^{-6} \mathrm{~S} \mathrm{~cm}^{-1}$ ). $\mathrm{NaOH}$ and $\mathrm{HCl}$ solutions were used for $\mathrm{pH}$ adjustments.

\subsection{Analysis}

Determination of the inorganic anions in the aqueous phase was accomplished by ionic chromatography performed using a Dionex ion chromatograph equipped with a suppressed conductivity detector, IonPac ${ }^{\circledR}$ AS19 capillary column (4 x $250 \mathrm{~mm}$ ), reagent free controller RFC-30 and Chromeleon Data system integrator. No attempt was made to fix the ionic strength in the solutions since it was observed to considerably alter the IC responses.

\subsection{Adsorbent}

Acidic $\gamma-\mathrm{Al}_{2} \mathrm{O}_{3}$ powder was provided from Sigma-Aldrich ${ }^{\circledR}$ and dried at $110{ }^{\circ} \mathrm{C}$ in a desiccator for $24 \mathrm{~h}$ to avoid the uptake of water vapor. The textural characteristics were evaluated by the adsorption of nitrogen $\left(\mathrm{N}_{2}\right)$ at $77 \mathrm{~K}$, and the BET (BrunauerEmmett-Teller) model (Autosorb-1, Quantachrome instruments). Potentiometric titration was used to estimate the $\mathrm{pH}_{\mathrm{PZC}}$ of $\mathrm{AA}$ [21]. 
The surface topographies of both fresh AA and AA adsorbed with fluoride were observed by means of scanning electron microscopy with energy dispersive spectroscopy SEM/EDS (S-520, Hitachi, Japan).

\subsection{Natural Organic Matter}

AHA stock solution was prepared by dissolving $0.2 \mathrm{~g}$ of AHA in its original form of sodium salt in $1 \mathrm{~L}$ of high purity water. $\mathrm{pH}$ was adjusted to 9 and stirred overnight to promote complete AHA dissolution. Finally $\mathrm{pH}$ was adjusted to 7 with $\mathrm{HCl}$. To remove undissolved AHA, the stock solution was filtered through $0.45 \mu \mathrm{m}$ membrane and diluted to $5 \mathrm{mgC} \mathrm{L}^{-1}$ for the adsorption experiments.

It is commonly accepted that some NOM compounds, notably those with light absorbing chemical structures such as aromatic rings, are known to absorb UV light at specific wavelengths, including $254 \mathrm{~nm}$. Therefore, it is also common to quantify NOM by measuring its absorption of UV light (UV254). UV254 can be normalized to dissolved organic carbon (DOC) to yield a specific UV absorbance (SUVA) value, which can be used to describe the aromaticity of the NOM being measured. The DOC was measured using a TOC analyzer (TOC-V CSN 5050 Shimadzu Corporation, Japan). The UV/Vis absorbance was measured in a Cary 50 spectrophotometer (Varian, USA) in the range $(200-750 \mathrm{~nm})$ using $5 \mathrm{~cm}$ path length quartz cell. The SUVA of AHA stock solution was determined at $254 \mathrm{~nm}$ and was calculated as follows [22]:

$$
S U V A_{254}=\frac{U V_{254}\left(\mathrm{~cm}^{-1}\right)}{\operatorname{DOC}\left(\mathrm{mg} \mathrm{L}^{-1}\right)} \times 100
$$

According to Karanfil et al. [23], SUVA at $254 \mathrm{~nm}$ provides a quantitative measure of aromatic content per unit concentration of carbon. Natural waters with high $\mathrm{SUVA}_{254}$ values $\geq 4 \mathrm{~L} \mathrm{mg}^{-1} \mathrm{~m}^{-1}$ have a relatively high content of hydrophobic, aromatic, 
and high molecular weight NOM fractions. Moreover, SUVA is a valuable characterization parameter for the assessment of NOM reactivity. It indicates the amenability of DOC removal during water treatment. In addition, the high-performance size exclusion chromatography (HPSEC) was used to characterize the adsorbability of NOM onto AA. The mobile phase was a MilliQ water buffered with sodium acetate (10 $\mathrm{mM})$ to $\mathrm{pH} 7$; the analytical conditions were $100 \mu \mathrm{l}$ volume injection of samples, $25^{\circ} \mathrm{C}$, 3066 Psi and a flow rate of $1 \mathrm{~mL} \mathrm{~min}^{-1}$.

\subsection{Adsorption and kinetic studies}

To predict the performance of AA in a given system, the adsorption capacity has to be experimentally determined by conducting isotherm tests. It is generally admitted that adsorption isotherms are considered as important data to elucidate the sorption mechanism by describing the affinity of adsorbed ions and the surface of the adsorbent and the composition of the solution at equilibrium. In this study, fluoride adsorption kinetic tests were performed using fresh AA to study the simultaneous adsorption of fluoride and NOM. In parallel, kinetic experiments were also conducted using preloaded AA to determine the effect of NOM adsorbed prior to fluoride adsorption. To perform these latter experiments, in the presence of NOM, the AHA was first equilibrated with activated alumina before the addition of fluoride to the bulk. For analysis of the residual concentrations of fluoride and NOM, the liquid phase was sampled and filtered through $0.45 \mu \mathrm{m}$ membrane.

All batch sorption experiments were carried out in a high-density polyethylene bottles and data were triplicated. The amount of adsorbed fluoride at equilibrium $\left(q_{e}\right.$, $\mathrm{mg} \mathrm{g}^{-1}$ ) was calculated using equation (Eq2):

$$
q e=\left(C_{0}-C_{e}\right) \times \frac{V}{m}
$$


Where $C_{o}$ and $C_{e}$ are the initial and equilibrium concentrations $\left(\mathrm{mg} \mathrm{L}^{-1}\right), V$ is the volume of solution (L) and $m$ is the adsorbent dose (g).

The removal efficiency was determined by computing the percentage sorption using $\operatorname{Eq}(3)$

$$
\% \text { Removal }=\frac{C_{0}-C_{e}}{C_{0}} \times 100
$$

\section{Results and discussion}

\subsection{Adsorbant characterization}

The total pore volume was determined from the adsorption of $\mathrm{N}_{2}$ at $77 \mathrm{~K}$ (sample weight: $0.1542 \mathrm{~g}$, outgassed at $250{ }^{\circ} \mathrm{C}$ ). The specific surface area of the sample and the average pore diameter were obtained with reference to the BET model. The mean pore width was calculated using the DFT (Density Functional Theory) method. Detailed textural characteristics of AA are summarized in Table 1. AA was found to possess a heterogeneous pore structure.

\section{Table 1: Surface characteristics of the activated alumina}

Fig. 1(a) shows the $\mathrm{N}_{2}$ adsorption/desorption isotherms of AA and the Fig. 1(b) the pore size distribution. According to the IUPAC classification, the corresponding isotherm can be classified as type IV characteristic of a mesoporous material. From the steepness of the adsorption isotherm, it can be seen that the mesopore structure is not well ordered and has a broad pore size distribution. In addition, evidence of the occurrence of open pores in the AA is shown by the presence of the hysteresis loop [24].

Fig. 1. $\mathrm{N}_{2}$ adsorption-desorption isotherms of AA sample at $77 \mathrm{~K}$ (a) and pore size distribution from adsorption branch (DFT histogram) (b) 
In order to further study the fluoride sorption onto AA, the surface topographies of both fresh AA and AA adsorbed with fluoride were observed with scanning electron microscopy (SEM). The corresponding micrographs are shown in Fig. 2. It was observed that the AA aggregates have various shapes and sizes. Moreover, Fig. 2(b) shows a cracked surface of AA. The spot elemental qualitative and semi-quantitative analyses of the AA surfaces were performed with energy-dispersive X-ray spectroscopy (EDS).

Fig. 2. SEM photomicrographs of the surface of AA before (a) and after (b)adsorption of fluoride

Fig. 3. EDS spectra of AA before (a) and after (b) adsorption of fluoride

EDS spectra represented in Fig. 3 show the appearance of a F signal with a mass percentage of $10.6 \%$ after contact with fluoride ions which shows an indirect evidence for fluoride adsorbed on the surface of AA.

On the other hand, a disappearance of the $\mathrm{Cl}$ signal was also observed confirming that there were two exchange sites on the surface of acidic alumina: sites of $\mathrm{Cl}^{-}$could be exchanged by fluorine or $\mathrm{OH}^{-}$since the selectivity sequence of anion adsorption onto alumina is $\mathrm{OH}^{-}>\mathrm{F}^{-}>\mathrm{Cl}^{-}[25]$.

\subsection{Adsorption kinetics}

All kinetic adsorption tests were carried out at a constant temperature of $25{ }^{\circ} \mathrm{C}$. UV absorbance at $254 \mathrm{~nm}$ of AHA in contact with AA was monitored over time. The 
initial AHA concentration used was $5 \mathrm{mg} \mathrm{L}^{-1}$. Fig. 4 shows a decrease in the AHA absorbance over time confirming the interaction of aromatic compounds and high molecular weight molecules with the AA; the decrease was mainly observed in the beginning of the run before almost constant values were observed beyond $200 \mathrm{~min}$ of experiment, confirming the partial adsorption of AHA.

Fig. 4. Variation of UV/Vis absorption ( $\boldsymbol{\Delta})$ and the removal yield of NOM in contact with AA (匹)

To predict the adsorption kinetics of fluoride ions onto AA in ultrapure water, kinetics models have been applied to the experimental data [26]. Kinetics models and parameters are summarized in Table 2 . The correlation coefficient for the pseudo $2^{\text {nd }}$ order model was greater than 0.999 supporting that chemisorption process was involved in fluoride sorption onto AA. Same results were reported in literature for the defluoridation of water using aluminium oxides [27,28].

Table 2: Pseudo-1st-order and -2nd-order constants for adsorption of fluoride onto AA

To investigate the effect of AA preloading on fluoride sorption kinetics, AHA was first allowed to adsorb onto AA. After reaching equilibrium (24 hours) a given amount of fluoride was spiked into the solution to obtain the desired concentration $\left(5 \mathrm{mg} \mathrm{L}^{-1}\right)$ and stirred for 24 additional hours.

Fig. 5 shows fluoride adsorption curves on both fresh and preloaded AA. It is observed that at the same initial sorbent concentration $\left(5 \mathrm{mg} \mathrm{L}^{-1}\right)$ the uptake of fluoride in absence of AHA was greater than that in presence of AHA. This change can be explained by two mechanisms: direct competition and pore blockage. In case of fresh AA direct 
competition for the surface active sites of adsorbent is the dominant mechanism while pore blockage becomes important at high AHA loading (using preloaded AA) [29]. In fact, the presence of AHA seems to block partially intraparticular pores within AA and therefore the fluoride ions continue to adsorb on micropores which are not blocked by high size molecules of AHA. Furthermore, it was notable that the presence of AHA did not affect the diffusional transport of fluoride.

In general, preloading effects can be expected if the NOM enters the adsorbent prior to fluoride ions. However, preloading occurs also if both are present in the water from the beginning of the operation. The reason is that most of the NOM is not as effectively adsorbed as the fluoride ions and therefore travels faster through the adsorber and preloads the fresh AA [29].

Fig. 5. Fluoride adsorption kinetics: $(\bullet)$ fluoride alone on fresh AA (๘) fluoride+AHA on fresh AA ( $\mathbf{\Delta})$ fluoride+AHA on preloaded AA

For a better understanding of the competitive mechanism, a simple method of comparison was chosen, namely the ratio $\mathrm{R}$ of the percentage removal of fluoride to the percentage of AHA over time:

$$
R=\frac{\text { \%removal of fluoride }}{\text { \%removal of } A H A}
$$

Fig. 6 shows that $\mathrm{R}$ decreased with time, meaning that the adsorption of fluoride was faster than the adsorption of AHA. In fact, AHA removal started to increase with increasing contact time which suggests that it could be advantageous to use shorter retention times in columns to inhibit NOM removal, since in water treatment process adsorption is performed in continuous mode. 
Fig. 6. Variation of the $\mathrm{R}$ ratio at different contact times.

Furthermore, it has to be noted that the accumulation of NOM is a function of the operation time of the fixed-bed adsorber. Therefore, it can be expected that the impact of pore blockage becomes even more critical when the adsorber is preloaded with NOM.

\subsection{Adsorption equilibrium}

An equilibrium time of 24 hours was chosen for isotherm tests since from kinetic studies it was found that equilibrium was reached before 24 hours.

\subsubsection{Adsorption of NOM}

Preliminary studies were carried out to characterize the adsorbability of NOM onto AA. The measured parameters of the NOM stock solution were $\mathrm{pH}=6.2, \mathrm{DOC}=33.75 \mathrm{mgC}$ $\mathrm{L}^{-1}$ and $\mathrm{SUVA}_{254}=11.21 \mathrm{~L} \mathrm{mg}^{-1} \mathrm{~m}^{-1}$. The calculated $\mathrm{SUVA}_{254}$ value confirmed the high content of complex, aromatic and high molecular weight.

Fig. 7. HPSEC Chromatogram of AHA before and after adsorption onto AA (Operating conditions: $\mathrm{V}_{\mathrm{inj}}=100 \mu \mathrm{l}$; adsorbent dose $=1 \mathrm{~g}_{\mathrm{AA}} ; \mathrm{C}_{\mathrm{HA}}=5 \mathrm{mg} \mathrm{L}^{-1}$; $\mathrm{T}=25{ }^{\circ} \mathrm{C}$; Eluant: Sodium Acetate $(10 \mathrm{mM}, \mathrm{pH}=7))$.

Fig. 7 shows the chromatograms of the solution of AHA before and after $24 \mathrm{~h}$ of equilibrium time. The results demonstrated that after reaching equilibrium only a fraction of NOM was adsorbed onto AA. Aromatic compounds were indeed adsorbed on the surface of the alumina, owing to the absorption observed at $254 \mathrm{~nm}$. The adsorption of AHA on alumina can take place mainly through water bridges, electrostatic attraction, formation of a coordinate link with a single donor group and 
formation of chelate complex. The ability of AHA to form stable complexes with AA results from the high content of oxygen-containing groups [30].

Batch study regarding the effect of both adsorbent dosage and initial concentration on AHA were carried out. Fig. 8 (a) shows a decrease in the AHA adsorbed amount with increasing AA dosage from 0.1 to $1.5 \mathrm{~g}$. The increase in the adsorbent dose may cause aggregation of adsorbent, and consequently, the number of available adsorption sites may decrease.

Fig. 8 Effect of adsorbent dose on AHA sorption $\left(\mathrm{C}_{\mathrm{AHA}}=5 \mathrm{mgC} \mathrm{L}^{-1}\right)$ (a) and effect of initial concentration on AHA sorption $\left(\mathrm{m}_{\mathrm{AA}}=0.1 \mathrm{~g}\right)(\mathrm{b})$

The effect of initial AHA concentration in the range $\left(2-20 \mathrm{mgC} \mathrm{L}^{-1}\right)$ on adsorption was investigated. Fig. 8 (b) shows that increasing initial concentration led to an increase in AHA adsorption onto AA.

\subsubsection{Adsorption of fluoride in ultrapure water}

Fig. 9 shows the effect of the adsorbent dose on fluoride sorption under two temperatures (25 and $\left.40{ }^{\circ} \mathrm{C}\right)$. The error bars represent the standard deviation of three identical experimental measurements. It is observed that the residual concentration decreased with an increase in the adsorbent dose independently of the temperature. This is probably due to an increase in the number of active sites of the AA surface.

Fig. 9 Effect of the adsorbent dose on fluoride sorption at $25^{\circ} \mathrm{C}(\bullet)$ and at $40^{\circ} \mathrm{C}(\boldsymbol{\square})$ (initial fluoride concentration $\mathrm{C}_{0}=5 \mathrm{mg} \mathrm{L}^{-1}$ ) 


\subsubsection{Simultaneous Adsorption of fluoride and NOM}

Simultaneous fluoride and AHA adsorption experiments were undertaken to clarify the competitive mechanisms occurring. Preliminary experiments indicated the absence of interactions between fluoride and AHA (initially at $5 \mathrm{mg} \mathrm{L}^{-1}$ ) since no change in the initial fluoride concentration was observed after a contact time of $24 \mathrm{~h}$. Both isotherms in presence and absence of AHA, represented in Fig. 10, show an S-type curve suggesting a cooperative adsorption: adsorbed fluoride ions promote the sorption of other fluoride ions thus acting as active sites. In presence of AHA this phenomena is observed for high values of $\mathrm{C}_{\mathrm{e}}$.

Fig. 10. Fluoride sorption isotherms: in absence of AHA $(\bullet)$ and in the presence of $\mathrm{AHA}(\mathbf{\square})$ (initial concentration of $\mathrm{AHA} \mathrm{C}_{\mathrm{AHA}}=5 \mathrm{mgC} \mathrm{L}^{-1}$ )

\subsection{Effect of $p H$}

AA exhibits a relatively large number of surface $\mathrm{OH}$ groups, which substantially determine its adsorption properties. Because of its amphoteric character, AA is strongly dependent on $\mathrm{pH}$ :at low $\mathrm{pH}$ (acidic medium, $\mathrm{pH}<\mathrm{pH}_{\mathrm{PZC}}$ ) the surface of $\mathrm{AA}$ is charged positively due to the protonation reactions.

$$
\equiv \mathrm{Al}-\mathrm{OH}+\mathrm{H}^{+} \square \equiv \mathrm{AlOH}_{2}^{+}
$$

At high $\mathrm{pH}$ (basic medium, $(\mathrm{pH}>\mathrm{pH}$ PZC), the deprotonation process changes the charge of the surface of alumina to negative:

$$
\equiv A l-O H \sqcup \equiv A l-O^{-}+H^{+}
$$

The polar character of the surface together with possible protonation or deprotonation processes of the $\mathrm{OH}$ groups makes AA ideally suited for the removal of fluoride, since it depends strongly on $\mathrm{pH}$. 
In this study, the $\mathrm{pH}$ was adjusted prior to the experiment, without the addition of a buffer, and the $\mathrm{pH}$ was thus shifting during the adsorption process and the removal of fluoride ions. However, such a shift was preferable to the adsorption competitions with ions from buffer (phosphate, carbonate, etc.). In Fig.11, the maximum fluoride removal efficiency was observed in $\mathrm{pH}$ in the range (6-8). The same results were found by Ghorai et al. [31] using a higher fluoride concentration (a maximum removal of $69 \%$ obtained at $\mathrm{pH} 7$, adsorbent dosage of $0.4 \mathrm{~g}$ and initial fluoride concentration of $13.8 \mathrm{mg}$ $\mathrm{L}^{-1}$ ). Besides, it is shown that below $\mathrm{pH} 4$ and above $\mathrm{pH} 7$, the increase in $\mathrm{pH}$ (significant deviations between the initial and final values) was perceptible resulting in an important release of $\mathrm{OH}^{-}$, confirming thereby the fluoride sorption onto uncharged AA surface through the formation of complexes in the inner-coordination sphere [32]:

$\equiv A l-O H+F^{-} \sqcup \equiv A l-F+O H^{-}$

By contrast, under alkaline conditions $(8<\mathrm{pH}<12)$, the $\mathrm{pH}$ of the solution decreased during adsorption probably as a result to the consumption of hydroxyl ions [33] $\equiv \mathrm{Al}-\mathrm{OH}+\mathrm{OH}^{-} \square \quad \equiv \mathrm{Al}-\mathrm{O}^{-}+\mathrm{H}_{2} \mathrm{O}$

At acidic $\mathrm{pH}$, where the surface of AA is highly protonated there is a greater increase in the attractive force between positively charged surface and negatively charged fluoride ions.

Besides, AA may be slightly dissolved in aqueous solutions and form, in contact with fluoride ions, various fluoride-aluminium complexes (e.g. $\mathrm{AlF}^{2+}, \mathrm{AlF}_{2}{ }^{+}, \mathrm{AlF}_{3}$, and $\mathrm{AlF}_{4}^{-}$). In this case, at acidic $\mathrm{pH}$, electrostatic repulsions between the positively charged species and the surface of AA are responsible of the decrease in the fluoride sorption for $\mathrm{pH}$ values below 5 [34]. 
Moreover, at $\mathrm{pH}$ higher than 9, the fluoride removal efficiency marginally decreased since the surface of AA acquires a negative charge at alkaline $\mathrm{pH}$. Also, the presence of hydroxyl ions competes with fluoride ions leading to a decrease in its uptake.

On the other hand, it was found that HA is adsorbed to alumina surface at $\mathrm{pH}<8$ via two possible mechanisms [35]:

A ligand-exchange reaction between the surface site and the dissociated form $\left(\mathrm{A}^{-}\right)$of HA:

$\equiv A l-O H+A^{-} \square \quad \equiv A l-A+O H^{-}$

Or an anion-exchange reaction of AHA with $\equiv \mathrm{Al}-\mathrm{OH}_{2}^{+}$.

The presence of AHA may then influence the interaction between fluoride and AA by altering its surface properties and stability. The adsorption of AHA lowered the surface charge of AA at acidic $\mathrm{pH}$ by decreasing its surface potential [36], which can explain the decrease in fluoride uptake in the presence of AHA.

Fig. 11. Effect of $\mathrm{pH}$ on the fluoride sorption (inset: variation of the $\mathrm{pH}$ values after fluoride sorption).

\subsection{Competitive effects with co-existing ions}

The fluoride adsorption behavior was also studied in the presence of co-existing ions that may influence the sorption process. The impact of the presence of sulfates, nitrates and phosphates ions on the removal yield is displayed in Fig. 12.

It is shown that phosphate had the most detrimental impact on fluoride removal. Undeniably, the presence of phosphates reduced the fluoride sorption onto AA. This reduction may be explained by the direct competition of fluoride and phosphates for the same active sites or due to the change in $\mathrm{pH}$ occurred by the presence of phosphate in the system or a combination of both processes. It is in agreement with the related 
literature. Indeed, Zheng et al. [37] showed that phosphate inner-sphere surface complexes were formed at the AA-water interface within a certain $\mathrm{pH}$ range. These surface complexes can cause permanent blockage of the active surface sites of alumina inhibiting thereby the fluoride sorption. In addition to surface complexes, aluminum phosphate precipitates may be formed.

Otherwise, the presence of nitrates and sulfates showed a slight improvement in fluoride removal efficiency. This may be attributed to a likely increase in the ionic strength of the solution and/or a weakening of lateral repulsion between adsorbed fluoride ions, which in turn lead to an increase in fluoride adsorption.

In addition, a change in the behavior of competition at lower adsorbent dosages is observed. This difference may be attributed to the $\mathrm{pH}$ variation of the solution in presence of AA. Considering the characteristic of AA to change the alkalinity of the solution, increasing its dosage modifies the $\mathrm{pH}$.

Nevertheless, Maliyekkal et al. [38] demonstrated that the presence of high sulfate amounts in water $\left(200 \mathrm{mg} \mathrm{L}^{-1}\right)$ reduces considerably the amount of fluoride removed by magnesia-amended AA (a decrease of 20-25\% of the adsorption capacity). However, no significant influence was noticed in the presence of phosphates and nitrates. Another relevant study using schwertmannite as adsorbent showed a slight reduction of the fluoride adsorption in the presence of phosphate and sulfate ions, while the existence of nitrates in solution led to an increase of fluoride uptake [39].

Fig. 12. Individual effect of co-existing ions on fluoride removal at different adsorbent doses. (Initial concentration of fluoride and all ions $=5 \mathrm{mg} \mathrm{L}^{-1}$ ) 
Kinetics of fluoride sorption in the presence of a mixture of interfering ions were also examined. As seen in Fig. 13, the simultaneous presence of competing anions decreased the individual adsorption capacities for fluoride anions if compared to the performances recorded above in the single anion tests. Kinetics of fluoride sorption in the presence of a mixture of interfering ions were also examined. A slight variation is noticeable from a span time of $180 \mathrm{~min}$ in presence of nitrates and sulfates. Their impact was almost the same over time. Moreover, there is no competition with phosphates till a time span of $600 \mathrm{~min}$ and effect of these ions increases over time and inhibits fluoride sorption gradually.

These differences in the behaviour confirms that changes in physicochemical characteristics of the solution are responsible for the decrease of the removal yield of fluorides: on the one hand, a variation in the ionic strength of the solution is caused by the existence of sulphates and nitrates; and on the other hand the presence of phosphates has an impact on the $\mathrm{pH}$ of the solution.

Fig. 13. Kinetic sorption of fluoride onto AA in the presence of co-existing ions:

$$
\text { fluoride alone }(\bullet), \mathrm{F}^{-}+\mathrm{SO}_{4}{ }^{2-}(\mathbf{\bullet}), \mathrm{F}^{-}+\mathrm{NO}_{3}^{-}(\boldsymbol{\Delta}), \mathrm{F}^{-}+\mathrm{PO}_{4}{ }^{2-}(+)
$$

\section{Conclusion}

The impact of the presence of humic acids on the sorption of fluoride by AA was studied. Equilibrium and kinetics experiments were undertaken to investigate both the single solute systems and the competitive adsorption. It was found that AA surface is receptive to both fluoride and AHA. HPSEC analyses confirmed the adsorption of aromatic compounds on the surface of alumina. It was also found that the presence of AHA in solution reduces the capacity of AA for defluoridation, probably because 
sorption of AHA to alumina may modify the surface characteristics and changes the fluoride retention behaviour of the surface by decreasing the surface charge of the adsorbent. However, similar trends were observed irrespective of the presence of AHA, showing that this latter did not affect the mechanisms of fluoride adsorption onto the AA surface.

In addition, the adsorption of fluoride was found to be largely affected by the presence of phosphates, while in the case of the presence of sulphates or nitrates fluoride uptake showed only a slight improvement.

\section{Acknowledgments}

The authors would like to thank J. Le Lanic and F. Gouttefangeas (CMEBA, University of Rennes 1) for the SEM/EDS analyses. We also wish to thank I. Soutrel for her help with chromatographic analyses.

\section{References}

[1] World Health Organization, Guidelines for Drinking Water Quality 3rd ed., WHO, Geneva, 2006, 375-377.

[2] Bhatnagar A, Kumar E, Sillanpää M. Fluoride removal from water by adsorptionA review. Chem. Eng. J. 2011;171:811-840.

[3] Tressaud A, editor. Advances in Fluorine Science, Fluorine and the Environment, Agrochemicals, Archaeology, Green Chemistry \& Water, Vol. 2, Elsevier: 2006.

[4] Mondal P, George S. A review on adsorbents used for defluoridation of drinking water. Rev. Environ. Sci. Bio/Technology 2014;14:195-210.

[5] Crittenden B, Thomas W J. Adsorption Technology \& Design. 1st ed., Elsevier Science and Technology Books: 1998.

[6] Yu Y, Yu L, Paul Chen J. Adsorption of fluoride by Fe-Mg-La triple-metal composite: Adsorbent preparation, illustration of performance and study of mechanisms. Chem. Eng. J. 2015;262:839-846. 
[7] Chatterjee S, De S. Adsorptive removal of fluoride by activated alumina doped cellulose acetate phthalate (CAP) mixed matrix membrane. Sep. Purif. Technol. 2014;125:223-238.

[8] Samarghandi MR, Khiadani M, Foroughi M, Zolghadr Nasab H. Defluoridation of water using activated alumina in presence of natural organic matter via response surface methodology. Environ. Sci. Pollut. Res. Int. 2016;23:887-897.

[9] Redman AD, Macalady DL, Ahmann D. Natural organic matter affects arsenic speciation and sorption onto hematite. Environ. Sci. Technol. 2002;36:28892896.

[10] Świetlik J, Sikorska E. Characterization of natural organic matter fractions by high pressure size-exclusion chromatography, specific UV absorbance and total luminescence spectroscopy. Polish J. Environ. Stud. 2006;15:145-153.

[11] Morales J, Manso JA, Cid A, Mejuto JC. Degradation of carbofuran and carbofuran-derivatives in presence of humic substances under basic conditions. Chemosphere 2012;89:1267-1271.

[12] Kumar S, Rawat N, Kar AS, Tomar BS, Manchanda VK. Effect of humic acid on sorption of technetium by alumina. J. Hazard. Mater. 2011;192:1040-1045.

[13] Wang X, Xu D, Chen L, Tan X, Zhou X, Ren a, Chen C. Sorption and complexation of $\mathrm{Eu}(\mathrm{III})$ on alumina: effects of $\mathrm{pH}$, ionic strength, humic acid and chelating resin on kinetic dissociation study. Appl. Radiat. Isot. 2006;64:414-421.

[14] Xiao J, Zhao L, Zhang W, Liu X, Chen Y. Effect of $\mathrm{pH}$, ionic strength, foreign ions, humic acid and temperature on $\mathrm{Zn}(\mathrm{II})$ sorption onto $\gamma-\mathrm{Al}_{2} \mathrm{O}_{3}$. Korean $\mathrm{J}$. Chem. Eng. 2014;31:253-261.

[15] Tang WW, Zeng GM, Gong JL, Liang J, Xu P, Zhang C, Huang B Bin. Impact of humic/fulvic acid on the removal of heavy metals from aqueous solutions using nanomaterials: A review. Sci. Total Environ.2014;468-469:1014-1027.

[16] Worch E. Adsorption Technology in Water Treatment: Fundamentals, Processes, and Modeling. Degruyter: 2012.

[17] Mouelhi M, Marzouk I, Hamrouni B. Optimization studies for water defluoridation by adsorption: application of a design of experiments. Desalin. Water Treat. $2015 ; 1-11$. 
[18] Janot N, Reiller PE, Zheng X, Croué J-P, Benedetti MF. Characterization of humic acid reactivity modifications due to adsorption onto $\alpha-\mathrm{Al}_{2} \mathrm{O}_{3}$. Water Res. 2012;46:731-740.

[19] Valencia S, Marín JM, Restrepo G, Frimmel FH. Application of excitationemission fluorescence matrices and UV/Vis absorption to monitoring the photocatalytic degradation of commercial humic acid. Sci. Total Environ. 2013;442:207-214.

[20] Ivanov P, Griffiths T, Bryan ND, Bozhikov G, Dmitriev S. The effect of humic acid on uranyl sorption onto bentonite at trace uranium levels. J. Environ. Monit. $2012 ; 14: 2968-2975$.

[21] Bouguerra W. Study of the removal of silica and boron by adsorption on activated alumina and coagulation flocculation: applications to Tunisian natural waters.[dissertation].Tunis: University of Tunis el Manar; 2009.

[22] Newcombe G, Morrison J, Hepplewhite C. S imultaneous adsorption of MIB and NOM onto activated carbon . I . Characterisation of the system and NOM adsorption. Science 2002;40:2135-2146.

[23] Karanfil T, A.Schlautman M, Erdogan I. Survey of DOC and UV measurement practices: With implications for SUVA determination. J. Am. Water Works Assoc. 2002;94:68-80.

[24] Diallo MS, Fromer NA, Myung SJ. Nanotechnology for sustainable development, Springer International Publishing: Switzerland; 2014.

[25] Gong W, Qu J, Liu R, Lan H. Adsorption of fluoride onto different types of aluminas. Chem. Eng. J. 2012;189-190:126-133.

[26] Çoruh S, Geyikçi F, Ergun ON. Adsorption of basic dye from wastewater using raw and activated red mud, Environ. Technol. 2011;32:11, 1183-1193.

[27] Alemu S, Mulugeta E, Zewge F, Chandravanshi BS. Water defluoridation by aluminium oxide-manganese oxide composite material, Environ.Technol.2014;35:15, 1893-1903.

[28] Hernández-Montoya V, Elizalde-González MP, Trejo-Vázquez R. Screening of Commercial Sorbents for Removal of Fluoride in Synthetic and Groundwater. Environ. Technol. 2007;28:595-607.

[29] Matsui Y, Yoshida T, Nakao S, Knappe DRU, Matsushita T. Characteristics of competitive adsorption between 2-methylisoborneol and natural organic matter 
on superfine and conventionally sized powdered activated carbons. Water Res. 2012;46:4741-4749.

[30] Kasprzyk-hordern B. Chemistry of alumina, reactions in aqueous solution and its application in water treatment. Adv. Colloid Interface Sci. 2004;110:19-48.

[31] Ghorai S, Pant KK. Equilibrium , kinetics and breakthrough studies for adsorption of fluoride on activated alumina. Sep. Purif. Technol. 2005;42:265-271.

[32] Szczepaniak W, Kościelna H. Specific adsorption of halogen anions on hydrous $\gamma-$ $\mathrm{Al}_{2} \mathrm{O}_{3}$. Anal. Chim. Acta 2002;470:263-276.

[33] Tombacz E, Dobos Â, Szekers M, Narres H D, Klumpp E, Dékany I. Effect of pH and ionic strength on the interaction of humic acid with aluminium oxide. Nano. $2000345,337-345$.

[34] Ku Y, Chiou H-M. The Adsorption of Fluoride Ion from Aqueous Solution by Activated Alumina. Water. Air. Soil Pollut. 2001;133:349-361.

[35] Wang X, Xu D, Chen L, Tan X, Zhou X, Ren a, Chen C. Sorption and complexation of $\mathrm{Eu}(\mathrm{III})$ on alumina: effects of $\mathrm{pH}$, ionic strength, humic acid and chelating resin on kinetic dissociation study. Appl. Radiat. Isot. 2006;64:414-421.

[36] Ghosh S, Mashayekhi H, Bhowmik P, Xing B. Colloidal stability of $\mathrm{Al}_{2} \mathrm{O}_{3}$ nanoparticles as affected by coating of structurally different humic acids. Langmuir 2010;26:873-879.

[37] Zheng T-T, Sun Z-X, Yang X-F, Holmgren A. Sorption of phosphate onto mesoporous $\gamma$-alumina studied with in-situ ATR-FTIR spectroscopy. Chem. Cent. J. 2012;6:26.

[38] Maliyekkal SM, Shukla S, Philip L, Nambi IM. Enhanced fluoride removal from drinking water by magnesia-amended activated alumina granules. Chem. Eng. J. 2008;140:183-192.

[39] Eskandarpour A, Onyango MS, Ochieng A, Asai S. Removal of fluoride ions from aqueous solution at low $\mathrm{pH}$ using schwertmannite. J. Hazard. Mater. 2008;152:571-579. 
Table 1: Surface characteristics of the activated alumina

\begin{tabular}{ll}
\hline Property & Value \\
\hline Total pore volume $\left(\mathrm{cm}^{3} \mathrm{~g}^{-1}\right)$ & 7.714 \\
Pore width $(\AA))(\mathrm{DFT})$ & 50.9 \\
Average pore diameter $(\AA)$ & 15.6 \\
Surface area $\left(\mathrm{m}^{2} \mathrm{~g}^{-1}\right)$ & 198 \\
pHPZC & 8.7 \\
\hline
\end{tabular}


Table 2: Pseudo-1st-order and -2nd-order constants for adsorption of fluoride onto AA

\begin{tabular}{lll}
\hline & Pseudo 1 $^{\text {st }}$ order & Pseudo 2 $^{\text {nd }}$ order \\
\hline equation & $\log \left(q_{e}-q_{t}\right)=\log q_{e}-\frac{k_{a d 1}}{2.303} t$ & $\frac{t}{q_{t}}=\frac{1}{K_{a d 2}} q_{e}^{2}+\frac{t}{q_{e}}$ \\
$\mathbf{K}_{\text {ad }}\left(\mathbf{m i n}^{-1}\right)$ & 0.006 & 1.450 \\
$\mathbf{R}^{2}$ & 0.965 & 0.999 \\
\hline
\end{tabular}




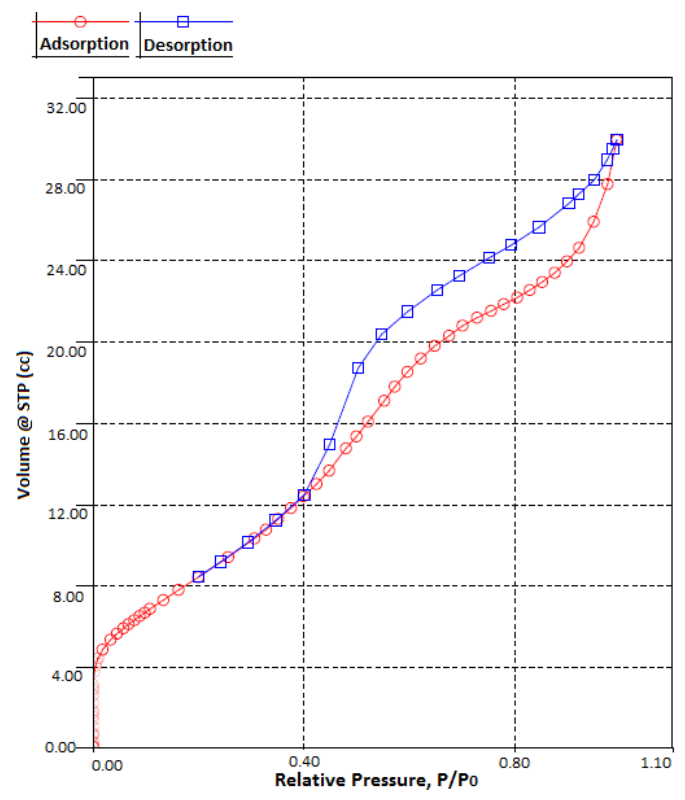

Fig. 1. (a) $\mathrm{N}_{2}$ adsorption-desorption isotherms of AA sample at $77 \mathrm{~K}$ 


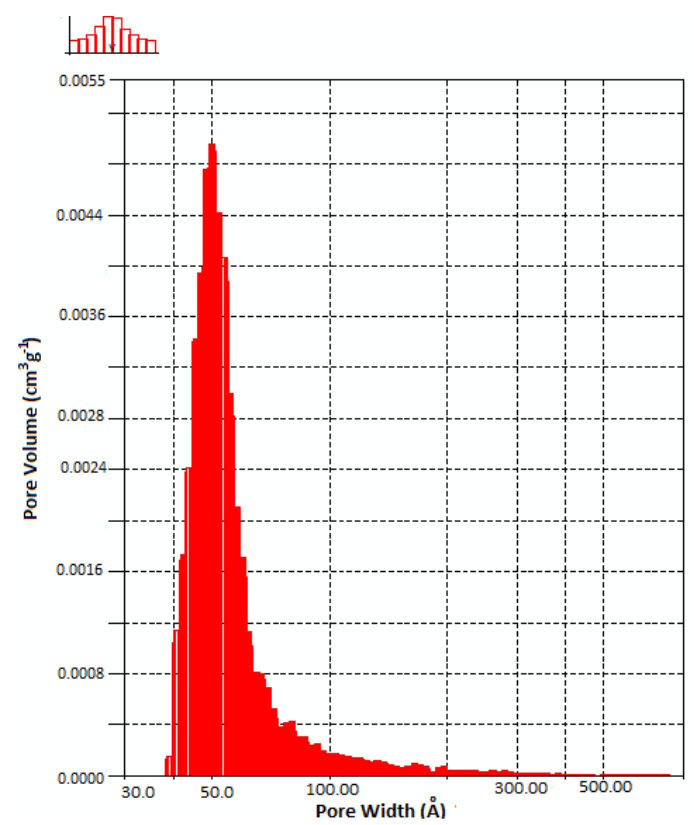

Fig. 1. $\mathrm{N}_{2}$ (b) pore size distribution from adsorption branch (DFT histogram) 


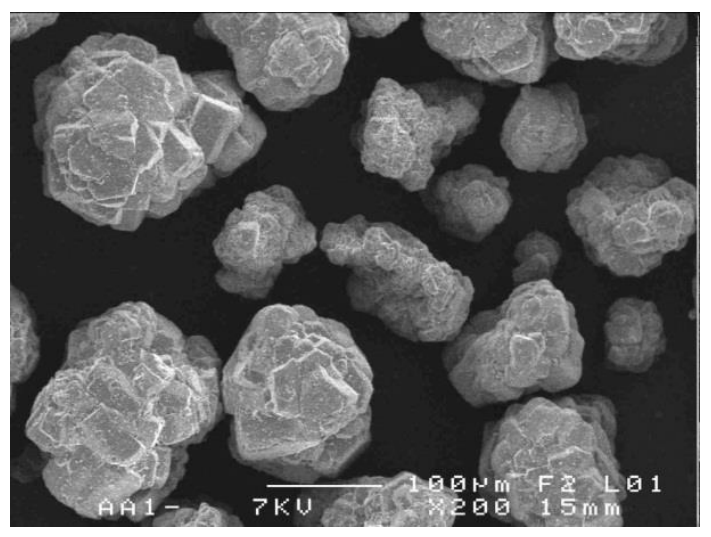

Fig. 2. (a) SEM photomicrographs of the surface of AA before adsorption of fluoride 


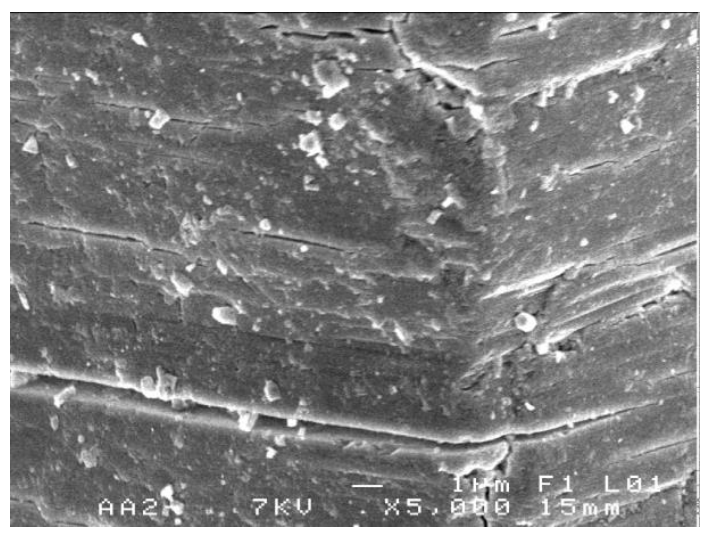

Fig. 2. (b)SEM photomicrographs of the surface of AA after adsorption of fluoride 


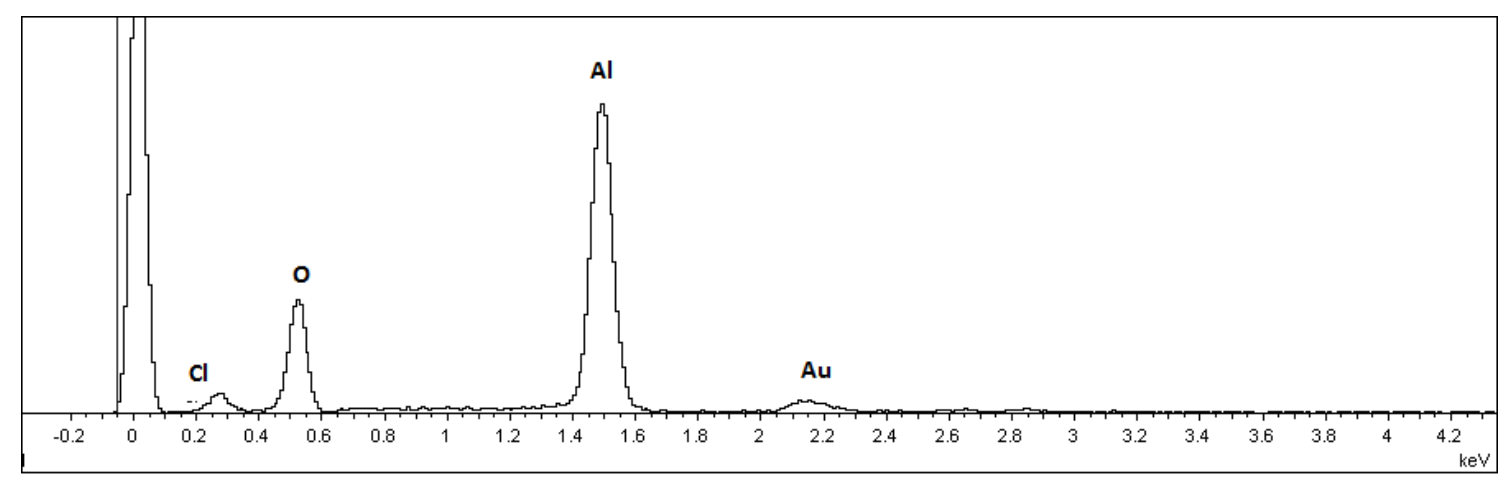

Fig. 3. (a) EDS spectra of AA before adsorption of fluoride 


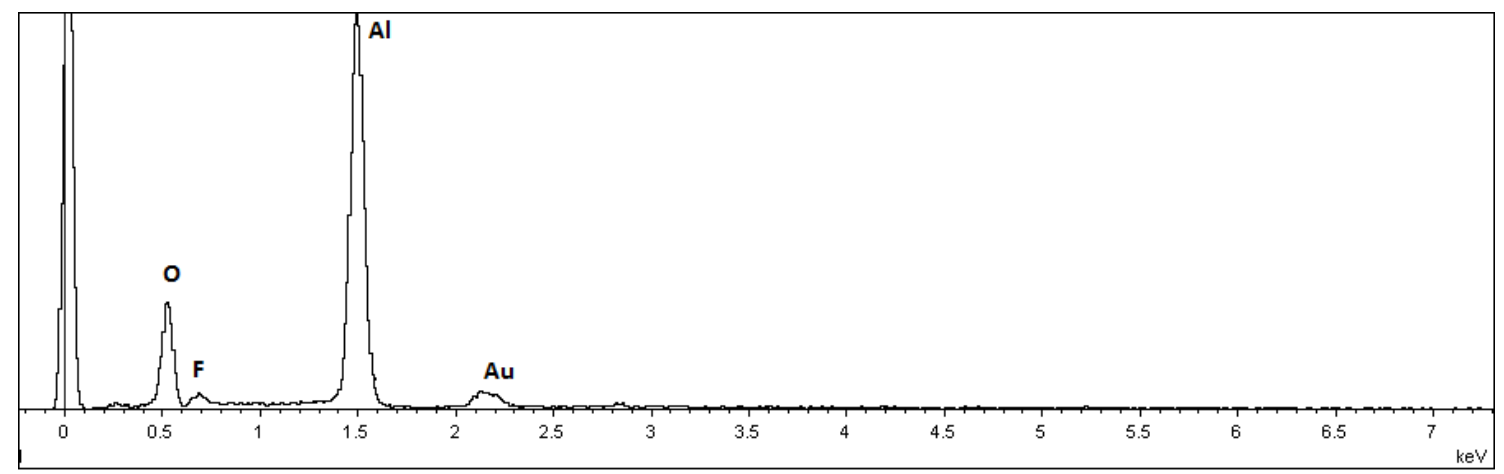

Fig. 3. (b) EDS spectra of AA and after adsorption of fluoride 


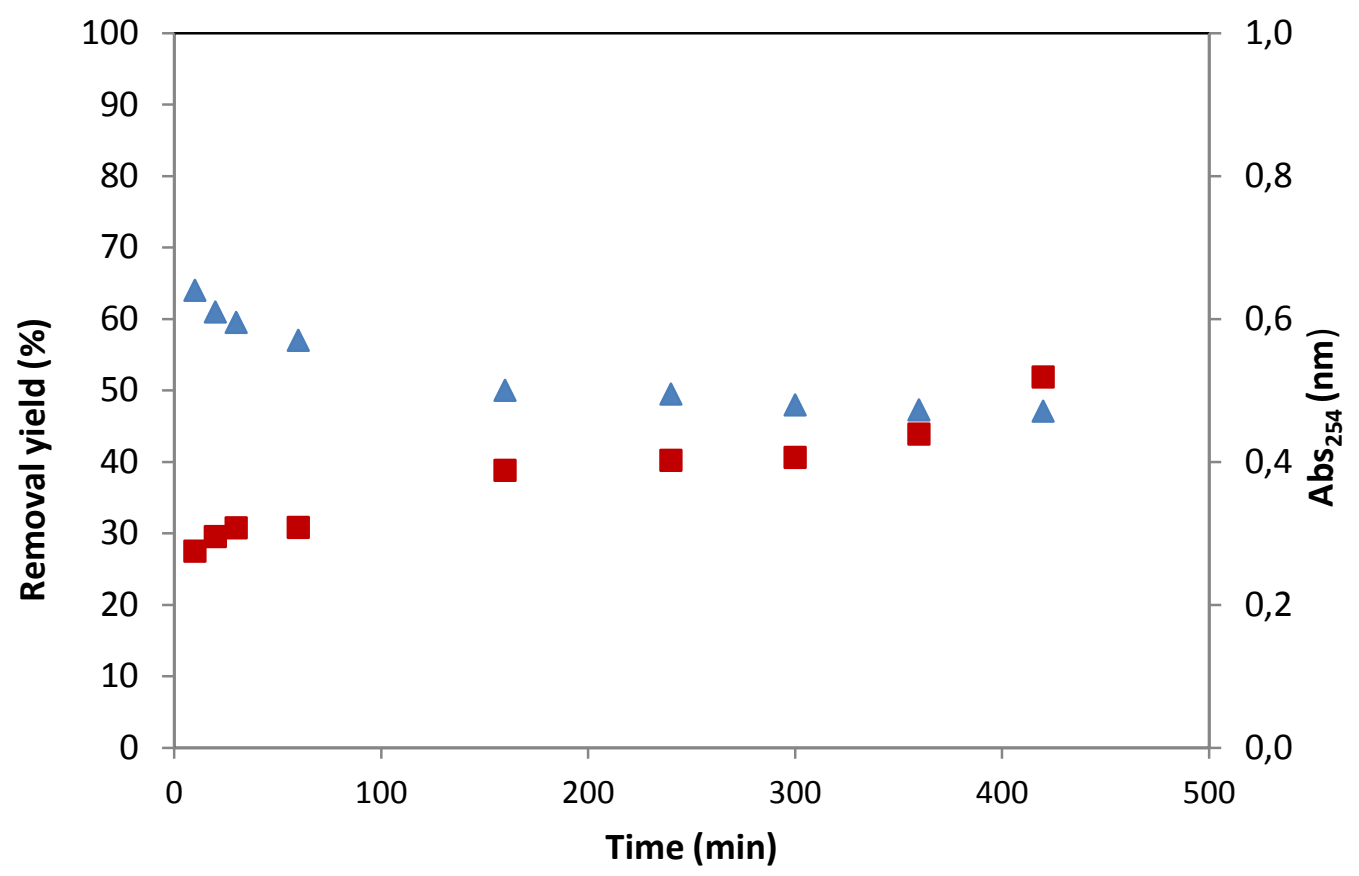

Fig. 4. Variation of UV/Vis absorption ( $\mathbf{A})$ and the removal yield of NOM in contact with AA ( $(\mathbf{)})$ 


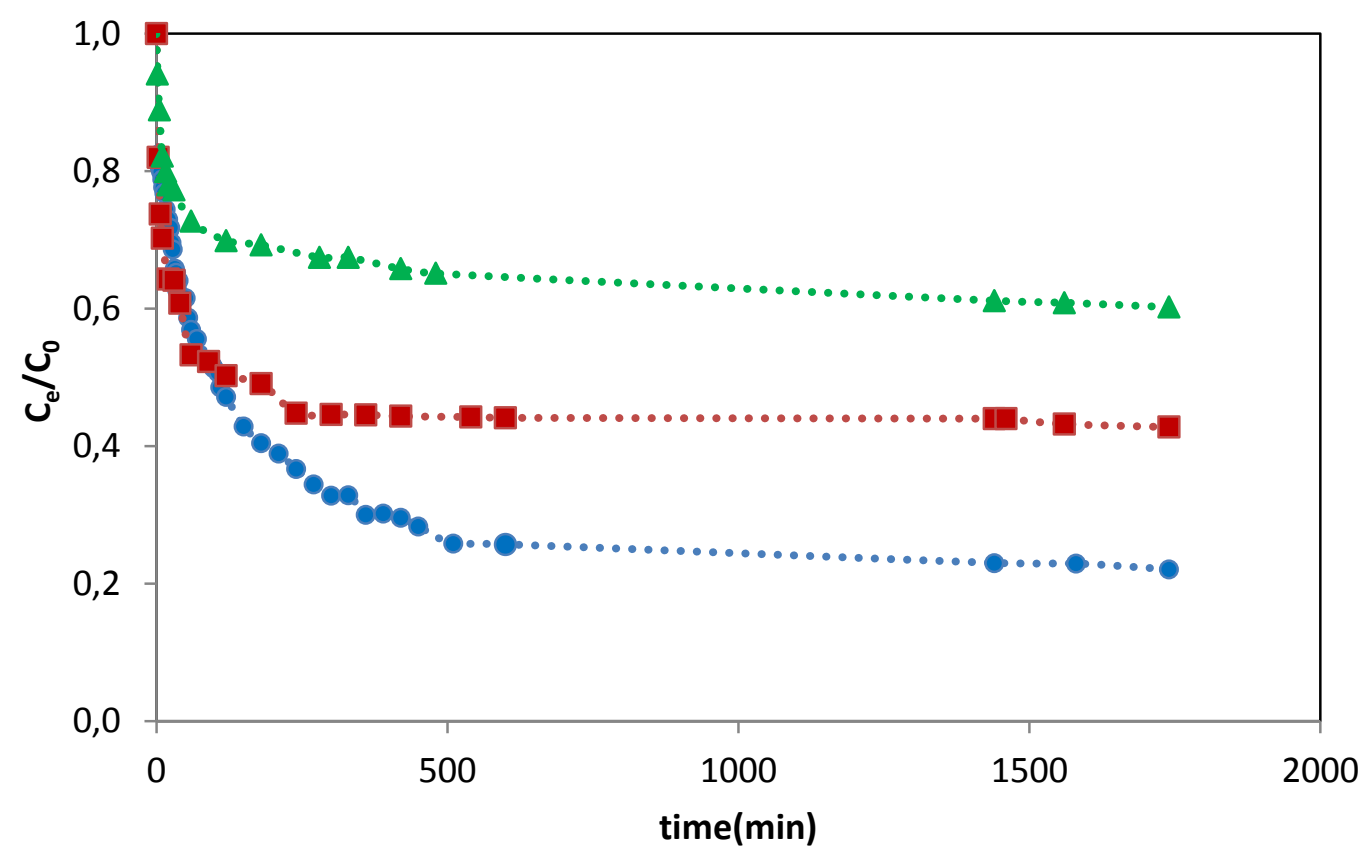

Fig. 5. Fluoride adsorption kinetics: $(\bullet)$ fluoride alone on fresh AA (•) fluoride+AHA on fresh AA ( $\boldsymbol{\Delta}$ ) fluoride+AHA on preloaded AA 


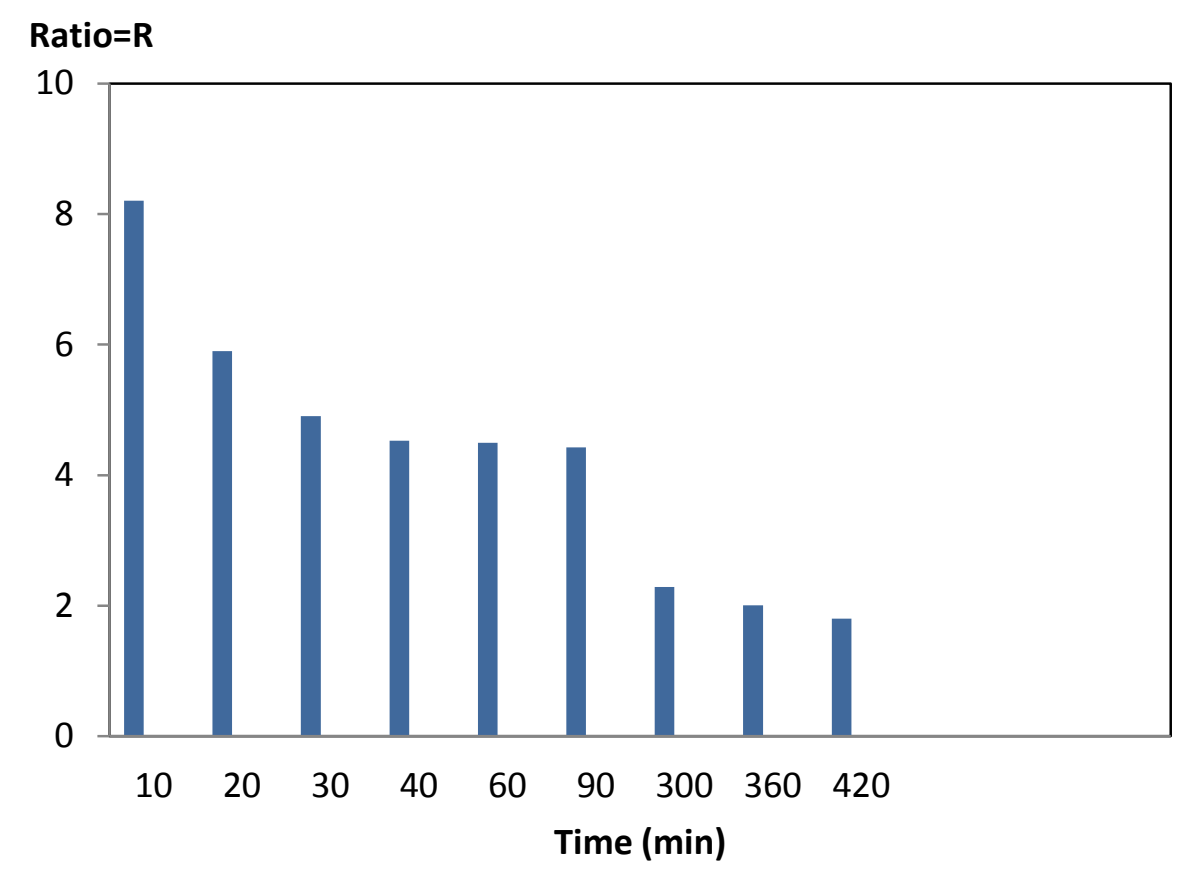

Fig. 6. Variation of the $\mathrm{R}$ ratio at different contact times 


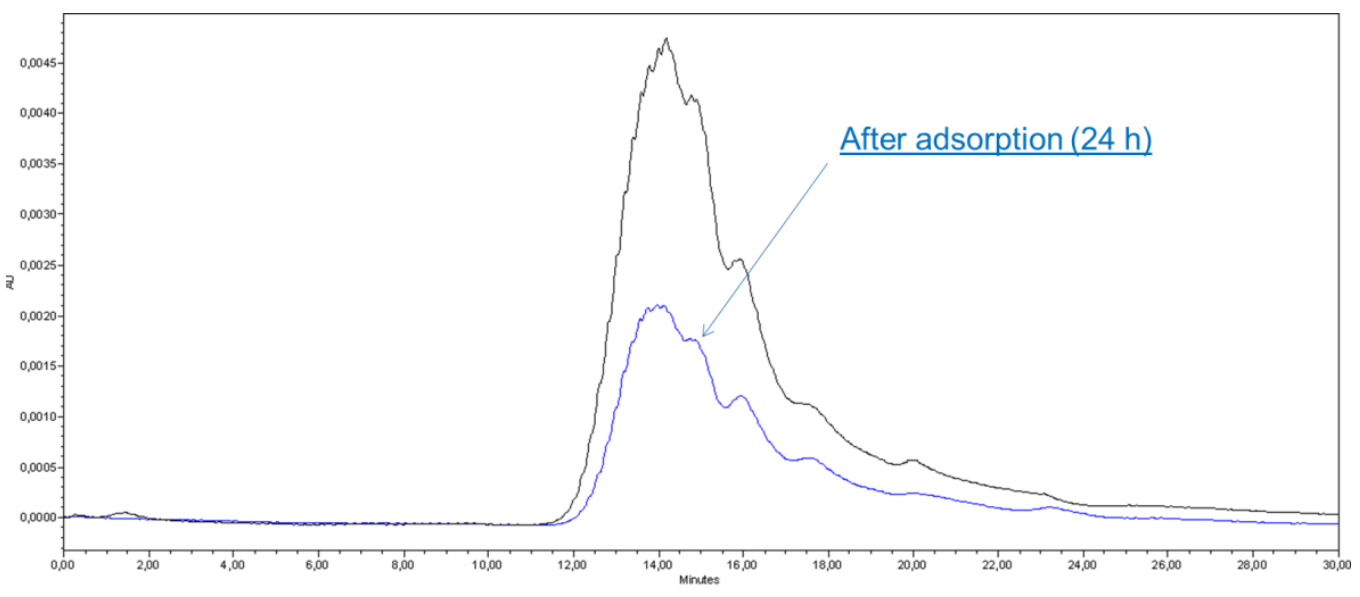

Fig. 7. HPSEC Chromatogram of AHA before and after adsorption onto AA

(Operating conditions: $\mathrm{V}_{\mathrm{inj}}=100 \mu \mathrm{l}$; adsorbent dose $=1 \mathrm{~g}_{\mathrm{AA}} ; \mathrm{C}_{\mathrm{HA}}=5 \mathrm{mg} \mathrm{L}^{-1} ; \mathrm{T}=25^{\circ} \mathrm{C}$;

Eluant: Sodium Acetate (10 mM, pH=7)) 


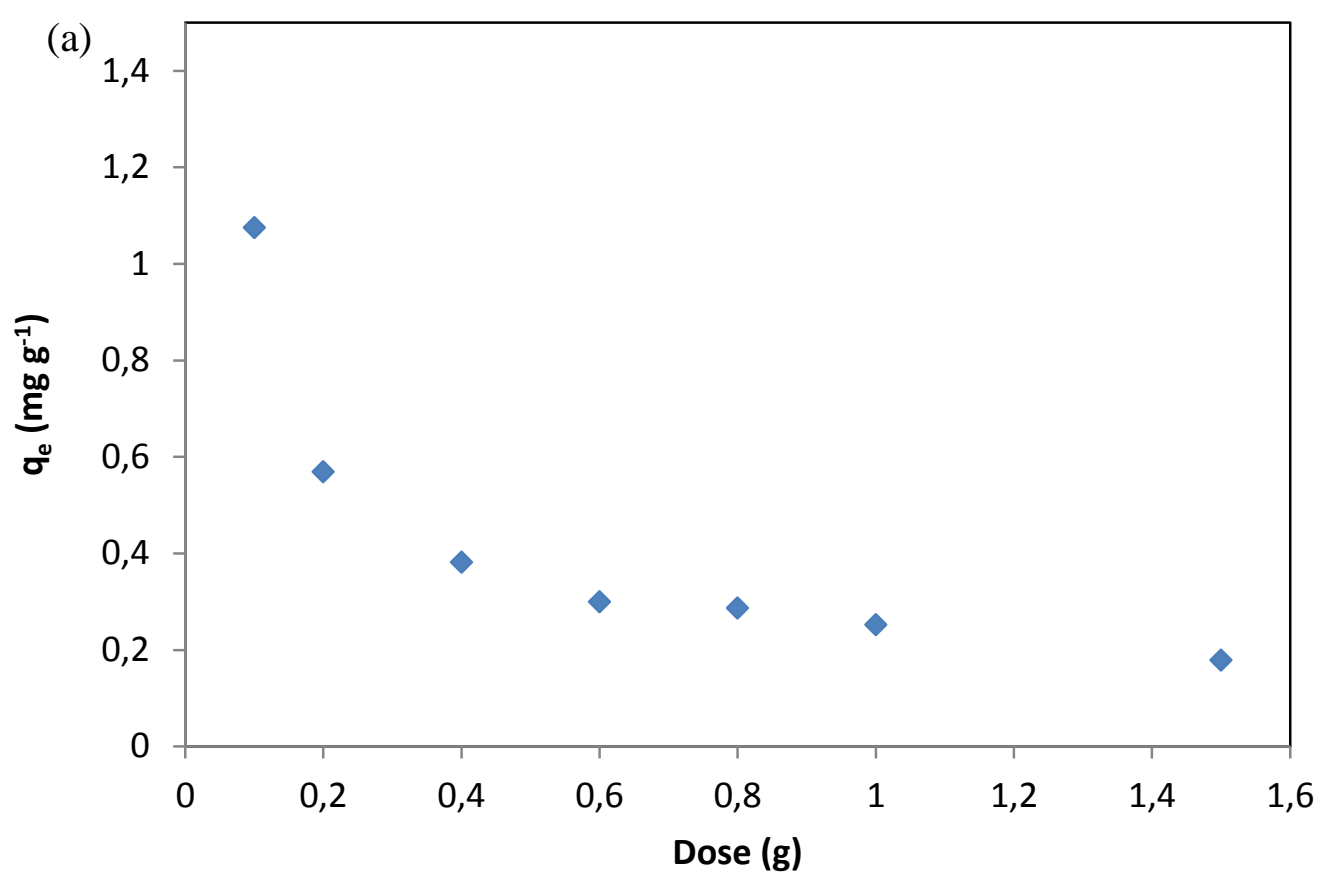

Fig. 8 (a) Effect of adsorbent dose on AHA sorption $\left(\mathrm{C}_{\mathrm{AHA}}=5 \mathrm{mgC} \mathrm{L}^{-1}\right)$ 


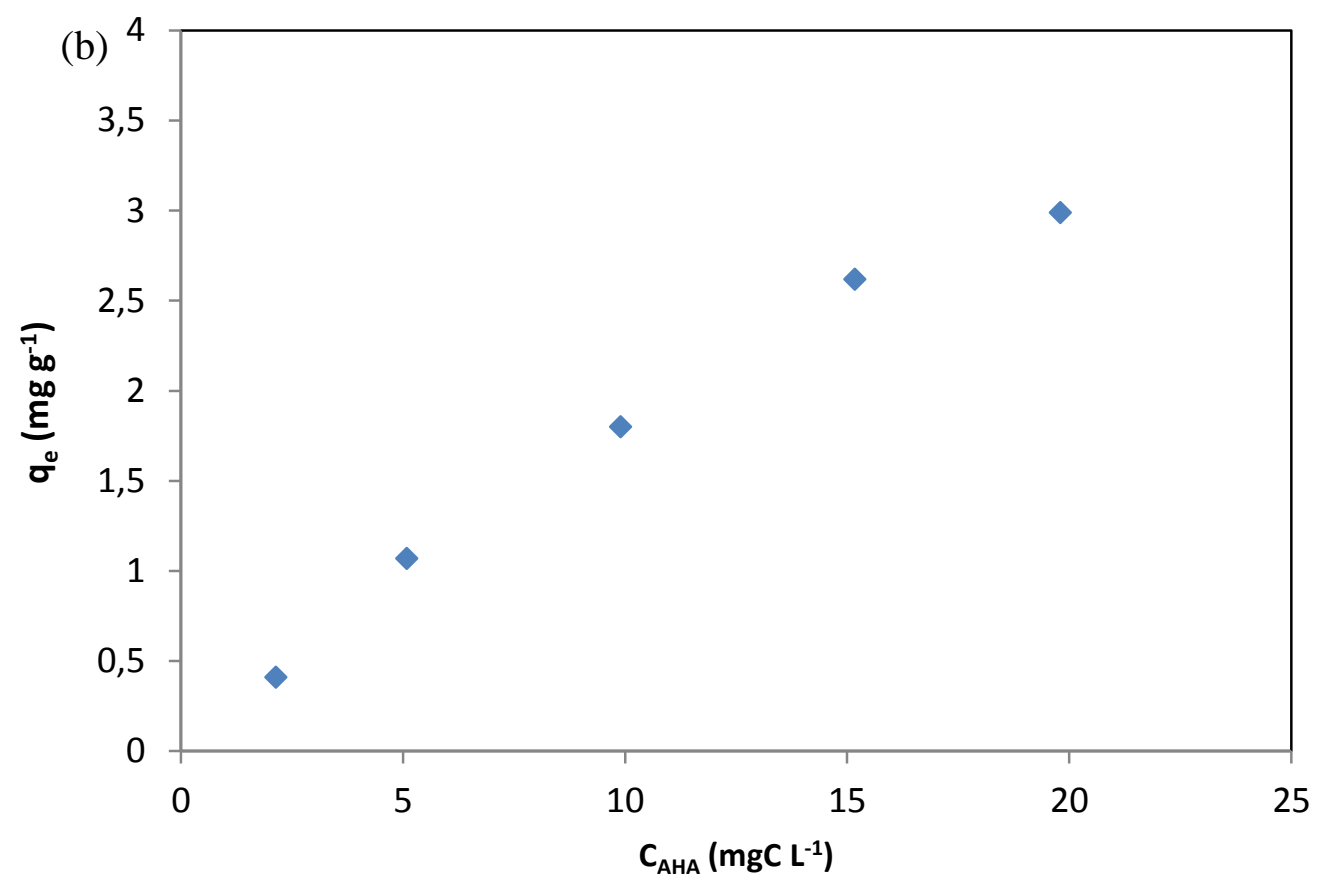

Fig. 8 (b) effect of initial concentration on AHA sorption $\left(\mathrm{m}_{\mathrm{AA}}=0.1 \mathrm{~g}\right)$ 


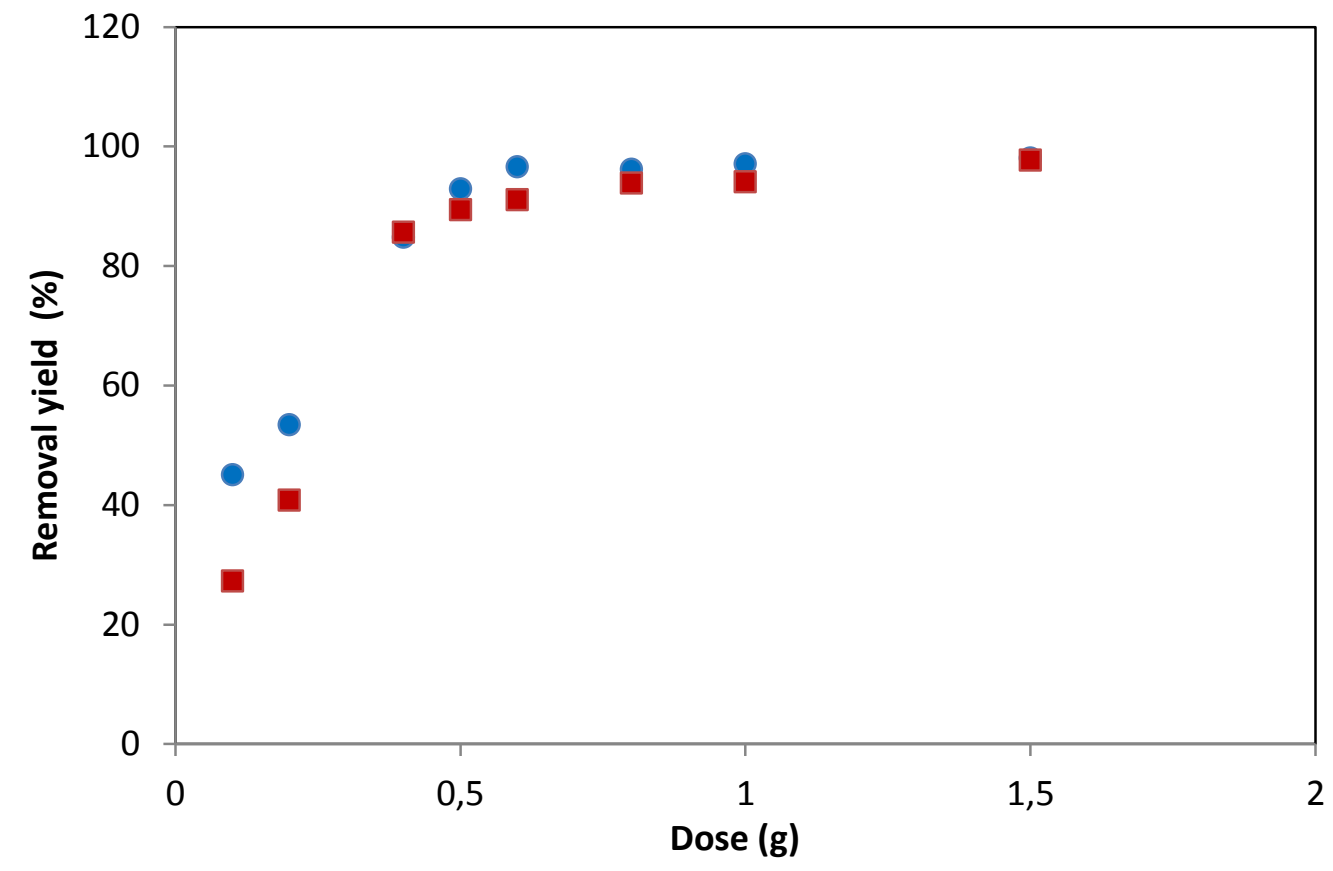

Fig. 9 Effect of the adsorbent dose on fluoride sorption at $25^{\circ} \mathrm{C}(\bullet)$ and at $40^{\circ} \mathrm{C}(\boldsymbol{\square})$ (initial fluoride concentration $\mathrm{C}_{0}=5 \mathrm{mg} \mathrm{L}^{-1}$ ) 


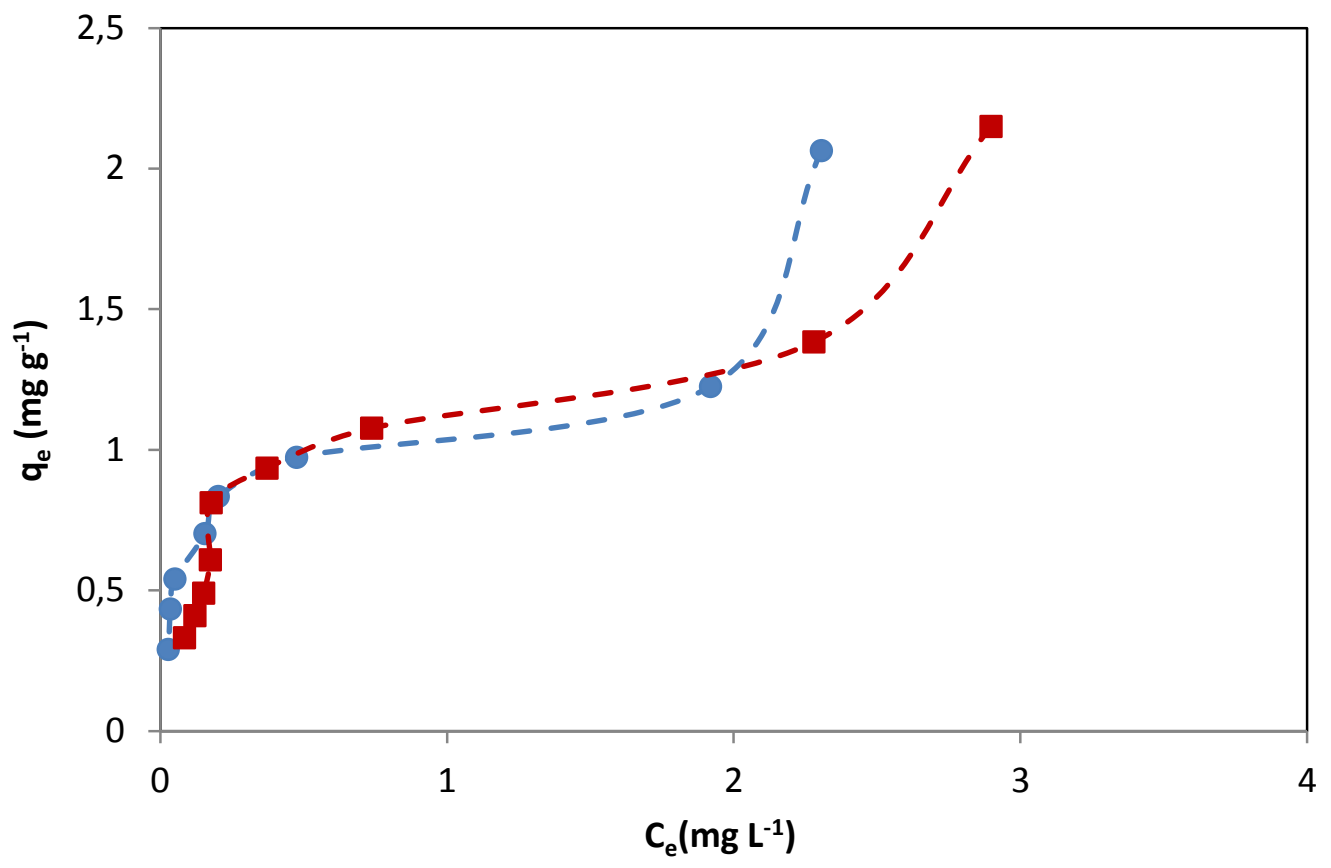

Fig. 10. Fluoride sorption isotherms: in absence of AHA (•) and in the presence of $\mathrm{AHA}(\boldsymbol{\square})$ (initial concentration of $\mathrm{AHA} \mathrm{C}_{\mathrm{AHA}}=5 \mathrm{mgC} \mathrm{L}^{-1}$ ) 


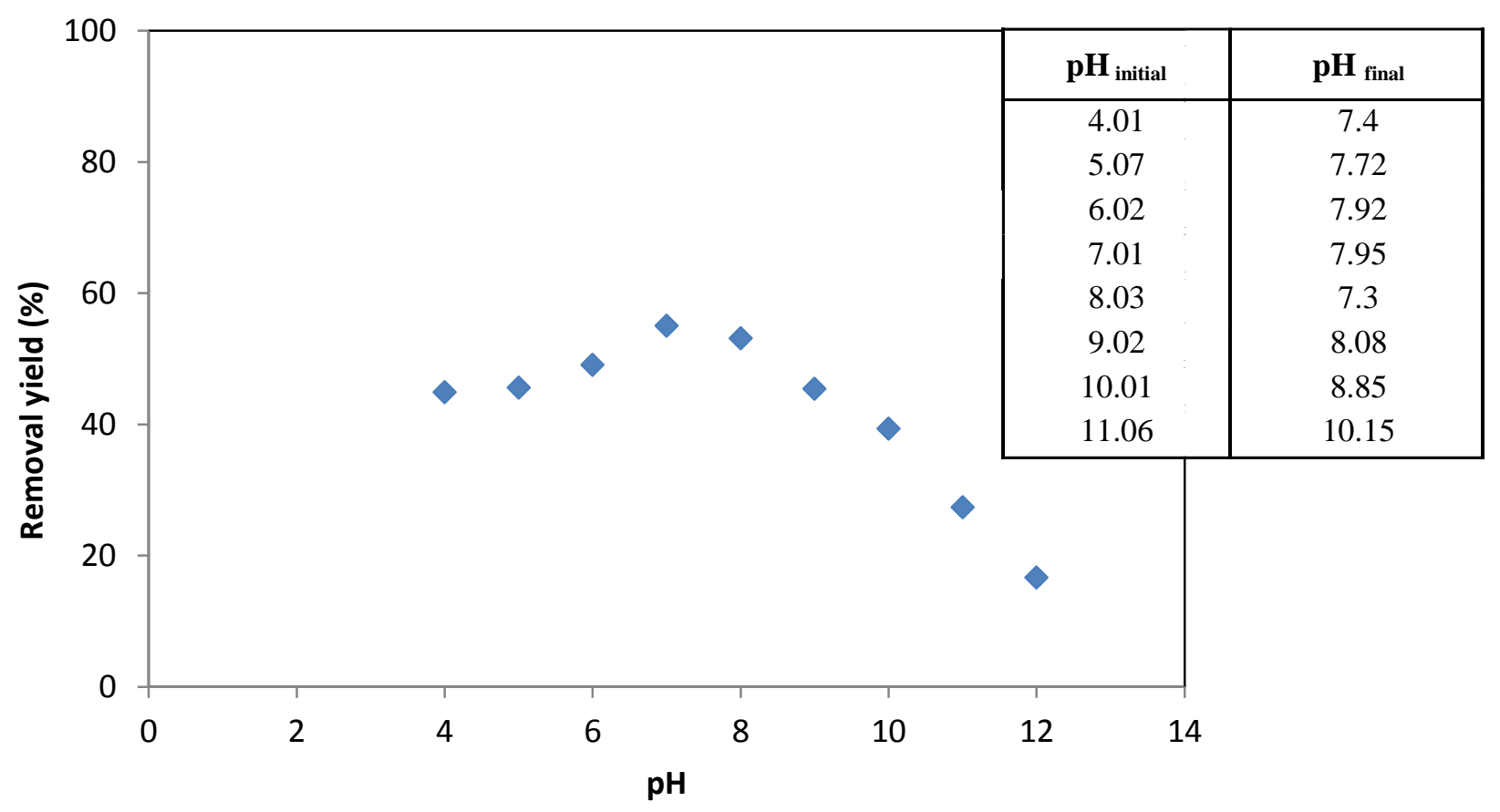

Fig. 11. Effect of $\mathrm{pH}$ on the fluoride sorption (inset: variation of the $\mathrm{pH}$ values after fluoride sorption) 


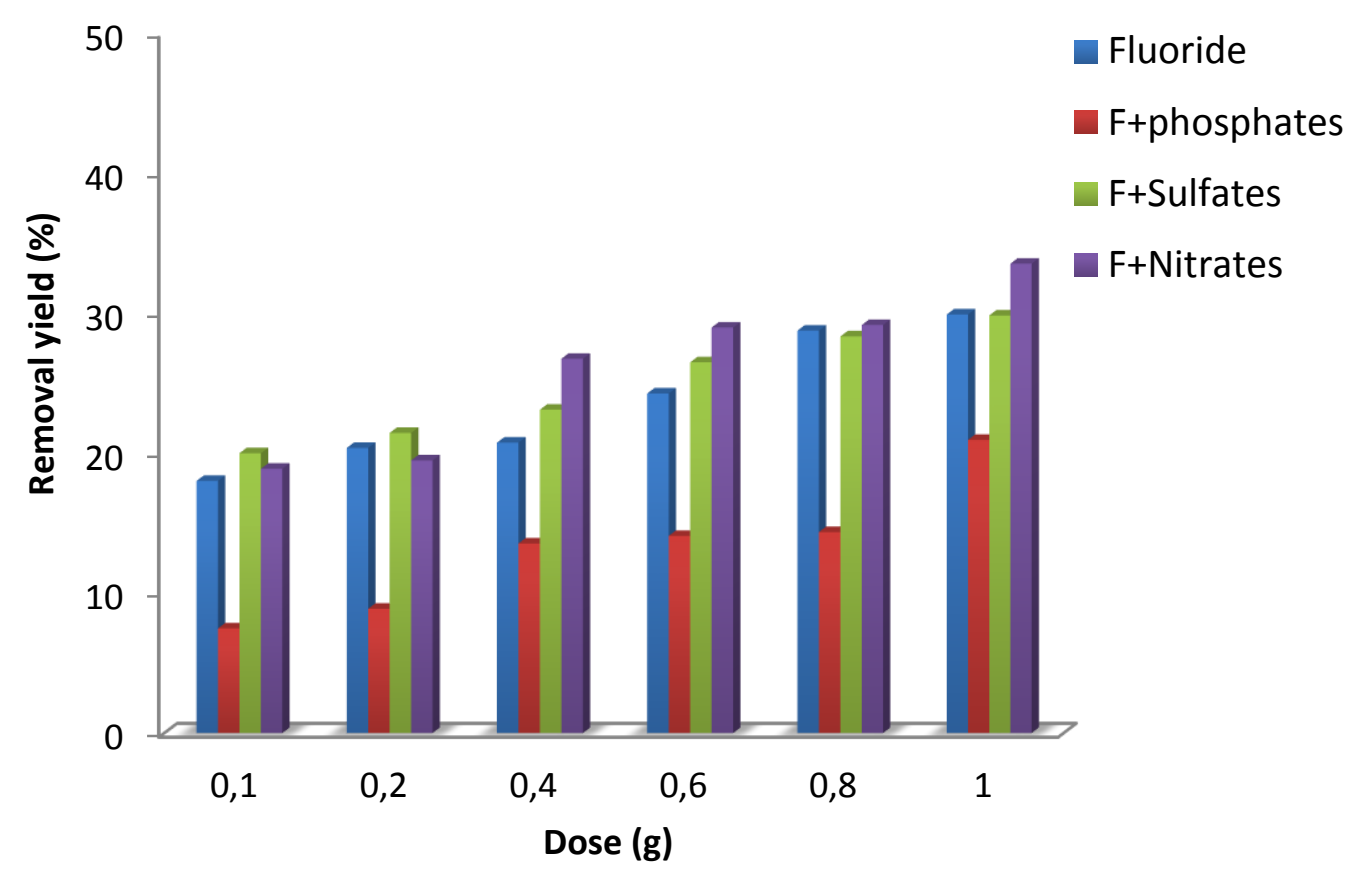

Fig. 12. Individual effect of co-existing ions on fluoride removal at different adsorbent doses. (Initial concentration of fluoride and all ions $=5 \mathrm{mg} \mathrm{L}^{-1}$ ) 


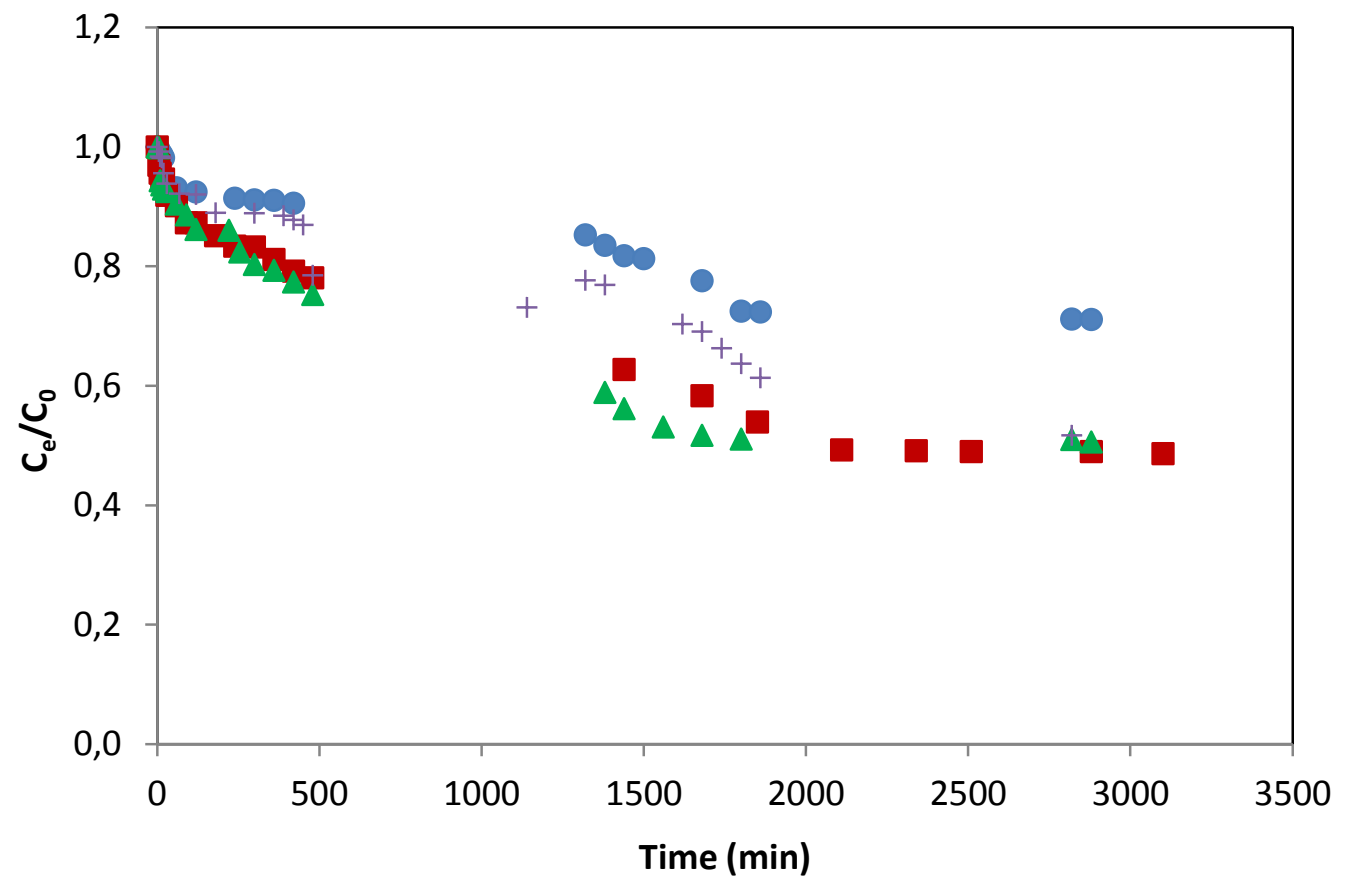

Fig. 13. Kinetic sorption of fluoride onto AA in the presence of co-existing ions: fluoride alone $(\bullet), \mathrm{F}^{-}+\mathrm{SO}_{4}{ }^{2-}(\boldsymbol{\bullet}), \mathrm{F}^{-}+\mathrm{NO}_{3}^{-}(\boldsymbol{\Lambda}), \mathrm{F}^{-}+\mathrm{PO}_{4}{ }^{2-}(+)$ 